Journal of Business and Management Research

ISSN: 2382-5219(Print); 2467-9267(Online)

January 2016, Vol.1, No.1, pp.1-13

DOI: http://dx.doi.org/10.3126/jbmr.v1i1.14547

\title{
Further Validation of Workplace Spirituality Scale in an Eastern Context
}

\author{
Arjun Kumar Shrestha* \\ School of Management, Kathmandu University, Lalitpur, Nepal
}

\begin{abstract}
Several scales for measuring workplace spirituality (WPS) are available. However, a majority of the available scales were developed in the Western context that may not be generalizable in an Eastern context. Petchsawang and Duchon (2009) developed a 22-item, four dimensional WPS scale with a sample from an Eastern Buddhist-centric culture for capturing WPS in an Eastern context. The purpose of this study was to assess the generalizability, dimensionality, and convergent and discriminant validity of this scale in another Eastern context, which has a strong tradition of Hindu culture. Confirmatory Factor Analyses were conducted on the data collected from 211 individuals, and results supported the four dimensions of the scale. Other statistical analyses demonstrated convergent and discriminant validity of the scale. Limitations of the study are highlighted, and suggestions for future research are discussed.
\end{abstract}

Keywords: Workplace Spirituality Scale, generalizability, convergent and discriminant validity

\section{Introduction}

The increasing competition among business firms has resulted in business reengineering, downsizing, and lay-offs which in turn have not only caused "a growing sense of insecurity among people both on economic and employment front" (Srirangarajan \& Bhaskar, 2011, p. 93) but also an "increased alienation and stress at individual level" (Polley, Vora, \& SubbaNarashimha, 2005, p. 50). These negative consequences have put strain on employees and their organizations to look for a meaningful work environment that focuses on employee well-being and caters employees' spiritual needs. As a result, workplace spirituality (WPS) has started gaining wider attention of scholars from diverse disciplines such as philosophy, transpersonal psychology, theology, sociology, sociology of religion, and management, which is evident in the surge of publication in different disciplines (e.g., Bhattacharya, 2013; Grant, O’Niel, \& Stephens, 2004; Hall \& Edwards, 2002; Krishnakumar \& Neck, 2002) in the past 15 years. Not only the academic community, but also the corporate sector has shown an interest in this subject as business organizations are conducting workshops, seminars, cultural change and corporate transformation programs, and so forth, which are aimed at harnessing the body, mind, and soul of employees to secure competitive advantage (Case \&Gosling, 2010).

Despite attracting wider attention of the research community and the corporate sector in the recent past, there is often a lack of agreement among scholars about what workplace spirituality means (Garcia-Zamor, 2003; Tourish \& Tourish, 2010). But, as Duchon and Plowman (2005) argue, employees do have spiritual needs, just as they have physical, psychological, and cognitive needs.

* Author Email: arjun@kusom.edu.np 
Thus, the upsurge of interest in spirituality at workplace can be considered as an acknowledgment of this fact.

It is an undeniable fact that for a systematic scientific inquiry of any construct, it needs to be defined and measured precisely. However, the problem or difficulty faced by organization scholars in defining or conceptualizing the construct WPS has posed a greater challenge for measuring it. In the absence of a valid, reliable, and widely acceptable scale having cross-cultural generalizability to capture the construct, scholars find it difficult to empirically examine the theoretical propositions put forward by several scholars highlighting the influence of WPS on different individual and organization related outcome variables. At the same time, the findings of empirical studies investigating the relationships between WPS and outcomes are also not far from criticisms.

Despite the absence of commonly agreed definition, many scholars in the West have attempted to develop scales for measuring workplace spirituality (e.g., Ashmos \& Duchon, 2000; Gomez \& Fisher, 2003; Liu \& Robertoson, 2011; Mascaro, Rosen, \& Morey, 2004; Milliman, Ferguson, Trickett, \& Condemi, 1999). Others have developed scales for the Asian context (e.g., Petchsawang \& Duchon, 2009; Sheng \& Chen, 2012). Likewise, Abdullah and Ismail (2013) validated the Malay version of Ashmos and Duchon's (2000) scale in the Malaysian school setting.

While reporting the development and an initial examination of a WPS scale, Petchsawang and Duchon (2009) highlighted a need for additional psychometric analysis of this scale with different samples. Though this scale is developed for a Buddhist context, it was conceptualized from the Western work contexts, using the pseudo-etic or imposed-etic (Triandis, 1994) approach. There is also a need to examine the generalizability of the scale in other Asian cultures. Nepal, with 81.3 percent Hindu population (Central Bureau of Statistics, 2012), provides a different cultural context to test the generalizability of this scale. This study examines the validity of the scale by using employees working in public and private organizations of Nepal.

\section{Theoretical Background}

In 1924, Mary Parker Follett in her book Creative Experience emphasized the need for attention to one's spiritual life in the workplace (as cited in Ratnakar \& Nair, 2012). Similarly, Weber (1958) also pointed out the need for developing management theories and practices that deemphasize individualism and materialism (as cited in Pandey \& Gupta, 2008). These calls suggest that interest in spirituality at workplace is not new. But surprisingly, individualism and materialism continued to flourish, especially in the West, and this topic failed to attract the interest of the academic community until the1980s. It was only after the late 1980s that scholars from different disciplines started conceptualizing this construct by utilizing different views. As Krishnakumar and Neck (2002) suggest, there are three views of spirituality - the intrinsic-origin view, the religious view, and the existentialist view. The intrinsic-origin view argues that spirituality originates from the inside of an individual and is not related to any particular religion. It is something which is beyond the rules of religion and is primarily based on an individual's inner consciousness. Religious view of spirituality, on the other hand, is attached to a particular religion as opposed to individual consciousness. The existentialist view is connected to the concepts such as what are we doing at the workplace and seeks answers to some of the fundamental questions such as "Why am I doing this work?", "What is the meaning of the work I am doing", "Where is the meaning of the work I am doing?", "Is there a reason for my existence and the organization's?" etc. (Krishnakumar \& Neck, 2002). 


\section{Defining Workplace Spirituality}

WPS, a topic that many scholars consider complex, diverse, and controversial, has seen a phenomenal growth of interest in recent years leading to many possible ways of defining it (Karakas, 2010). As a result, a plethora of definitions of WPS abounds in the literature. Mirvis (1997) defined it as meaning in work and sense of community; Mitroff and Denton (1999) defined it as the "basic feeling of being connected with one's complete self, others, and the entire universe" (p. 83); Giacalone and Jurkiewicz (2003) defined it as "a framework of organizational values evidenced in the culture that promote employees' experience of transcendence through the work process, facilitating their sense of being connected to others in a way that provides feelings of completeness and joy" (p. 3), and Duchon and Plowman (2005) defined it as "a workplace that recognizes that employees have an inner life that nourishes and is nourished by meaningful work that takes place in the context of community" (p. 807).

Although hundreds of definitions of WPS appear in academic articles from diverse academic fields, Pawar (2008) posits that WPS can be interpreted as "an organization's facilitation of employee experience of spirituality at work" (p. 544) or "employee experiences of spirituality at work" (p. 545). This study utilizes the definition by Petchsawang and Duchon (2009), which states that WPS is "having compassion towards others, experiencing a mindful inner consciousness in the pursuit of meaningful work that enables transcendence" (p. 465). This definition is in line with Pawar's (2008) interpretation of WPS as employees' experience of spirituality at work.

\section{Dimensions of Workplace Spirituality}

Scholars agree that WPS is a multi-dimensional construct. For example, Mitroff and Denton (1999) suggested senses of connection with oneself, others, and workplace as dimensions of WPS. Ashmos and Duchon's (2000) study indicated 'sense of inner life', 'meaningful work' and 'community' as three dimensions of WPS. Pawar (2009) identified four dimensions of WPS, viz. 'organizational norms', 'innerself', 'connectedness', and 'personal fulfillment'.

Other attempts to identify the dimansionality of WPS include Kolodinsky, Giacalone, and Jurkiewicz's (2008) study, which indicated 'organizational norms', 'connectednesses', and 'alignment with organizational value' as the dimensions of WPS. Liu and Robertson (2011) proposed a new theoretical conceptualization and developed a scale of WPS having three dimensions 'interconnection with a higher power', 'interconnection with human beings', and 'interconnection with nature and all living things'.

To resolve the ambiguities in the dimensionality of WPS, attempts have been made by several scholars to find out some common themes. For example, Chawla and Guda (2010), while reviewing different definitions that appear in the literature, identified common themes such as 'sense of community', 'inner life', 'meaningful work' and 'transcendence' as different dimensions of WPS. Srirangarajan and Bhaskar (2011) also noted certain key characteristics of WPS that repeatedly appear in the literature. Based on these characteristics, they shortlisted 15 key dimensions of WPS.Similarly, Petchsawang and Duchon (2009), in their attempt to develop a WPS scale in an Eastern context, found that five different themes - 'connection', 'compassion', 'mindfulness', 'meaningful work', and 'transcendence' often surfaced in the WPS literature. However, their study confirmed only four dimensions and could not confirm the 'connection' dimension. The definitions of four dimensions provided by these authors are as follows: 
Compassion: "A deep awareness of and sympathy for others and a wish to relieve their suffering that leads to responsibility for another who is less fortunate or suffering" (p. 461).

Mindfulness: "A state of inner consciousness in which one is aware of one's thoughts and actions moment by moment. It is about a person's mind being present, not wandering with past, future thoughts or distractions." (p. 461).

Meaningful work: "One's experience that his/her work is a significant and meaningful part to his/her life, the meaning is beyond the material rewards and creates a sense of joy and energy at work" (p. 463).

Transcendence: "A connection to higher power but does not involve a feeling of being connected with God” (p. 463).

Based on these definitions of four different dimensions of WPS, Petchsawang and Duchon (2009) initially generated 37 items (including four items of 'connection' dimension) and performed Confirmatory Factor Analysis (CFA) to validate the scale. The analyses resulted in a four dimensional 22-item WPS scale. This study attempted to further validate this scale in another Eastern cultural context with samples from different organizations in Nepal.

\section{Method}

This section first presents a brief description of the participants, the scale used for collecting the data and the responses received from the participants. It then describes the process of assessing the convergent and discriminant validity of a scale.

\section{Participants and Measures}

The participants of this study included 330 employees from 22 different public and private organizations in Nepal. Instruments were translated from English to Nepali language with the help of a professional translator. Items in English as well as in Nepali language were simultaneously provided in the questionnaire. Out of 330 questionnaires distributed, a total of 215 questionnaires were returned, yielding a response rate of 65 percent. Out of 215 questionnaires received, four questionnaires were discarded as the respondents did not respond to more than 25 percent of the items. Remaining 211 questionnaires had no missing responses on the scale items.

The questionnaire included 22 items from Petchsawang and Duchon's (2009) workplace spirituality scale. Participants responded to these items on a 5 point Likert type scale and ranged from 1 (strongly disagree) to 5 (strongly agree). Information about five demographic variables (age, gender, position, educational qualification, and tenure in the organization) was also collected.

\section{Assessment of Convergent and Discriminant Validity}

Convergent validity assesses the extent to which the items that are indicators of a specific construct converge or share a high proportion of variance in common (Hair, Black, Babin, \& Anderson, 2010). There are three different ways of estimating relative amount of convergent validity. One way of estimating it is the size of factor loading. If the standardized loadings of the items are statistically significant and if the standardized estimate values are .50 or higher, the construct is said to have convergent validity. Another way of determining convergent validity is the average variance extracted (AVE). Variance extracted not only explains the average percentage of variation explained but also 
demonstrates summary measure of convergence among a set of items representing a latent construct (Indartono \& Wulandari, 2013). According to Hair et al. (2010), the AVE can be calculated by using standardized loadings:

$$
A V E=\frac{\sum_{i=1}^{n} L_{i}^{2}}{n}
$$

The $L_{i}$ represents the standardized factor loading and $i$ is the number of items. An AVE of .50 or higher suggests adequate convergence (Hair et al., 2010).

Coefficient alpha, the measure of internal consistency reliability, is also an indicator of convergent validity. If the value of coefficient alpha is greater than .70 or if the value is between .60 and .70 , but other indicators of convergent validity are good, the construct can be considered as having good convergent validity (Hair et al., 2010). Convergent validity can also be checked by comparing the squared correlations between constructs and the AVE of each construct. If the values of AVE exceed squared correlations, then the constructs have good convergent validity (Indartono \& Wulandari, 2013).

Another way of assessing validity of a scale is discriminant validity which indicates "the extent to which a construct is truly distinct from other constructs" (Hair et al., 2010, p. 710). A measure is said to have good discriminant validity if a construct whose discriminant validity is being assessed is not highly correlated with another theoretically different construct. Indartono and Wulandari (2013) provide the following formula that can be used to assess the extent to which two construct overlap.

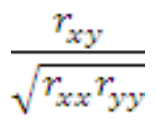

In this formula, $r_{x y}$ is the correlation between the constructs $x$ and $\mathrm{y}, \mathrm{r}_{x x}$ is the reliability of construct $x$, and $r_{y y}$ is the reliability of construct $y$. The value greater than .85 indicates that there is a greater overlap between the two constructs and they are likely to measure the same thing.

\section{Results}

The demographic profile of the respondents is shown in Table 1.The mean and standard deviation of scale items and inter-item correlation matrix are shown in Table 2.

Normality of scale items were assessed by conducting Kolmogorov-Smirnov and Shapiro-Wilk tests. Although test results were significant, the Q-Q plots and histograms did not depart from the expected forms and the skewness and kurtosis values were within \pm 1.20 , allowing for the analyses to proceed. Moreover, reliabilities of each dimension of WPS scales were assessed using Cronbach's alpha. The Cronbach's alpha values of four dimensions of WPS scale are reported in Table 3. Except the compassion dimension, which has relatively low value of Cronbach's alpha $(\alpha=.60)$, other dimensions have acceptable values of reliability $(\alpha>=.70)$. The Cronbach's alpha for the entire scale is .89 . 


\section{Generalizability and Dimensionality of WPS Scale}

The dimensionality of WPS scale was assessed by using Confirmatory Factor Analysis (CFA). It was employed to assess the model fit by specifying a measurement model. The measurement model consisted of four latent variables (compassion, meaningful work, transcendence, and mindfulness) and their indicators (scale items). The measurement model with 22 items showed an acceptable fit: $x^{2}=$ 404.79, $d f=203, p=.00, \mathrm{RMSEA}=.06, \mathrm{CFI}=.95, \mathrm{IFI}=.95$. The standardized loadings (estimates), and squired multiple correlations $\left(R^{2}\right)$ are shown in Table 3. All factor loadings have values above .30 and are significant $(p<.05)$.The results of CFA and reliability analysis clearly indicate that the WPS scale developed in Thai context is generalizable to Nepali context and all four dimensions are neatly reproduced in this context.

Table 1

Socio-demographic Profile of Respondents

\begin{tabular}{lr}
\hline Variables & Frequency $(\%)$ \\
\hline Age & \\
25 years or less & $58(27.5)$ \\
$26-35$ years & $117(55.5)$ \\
$36-45$ years & $19(9.0)$ \\
46 year or above & $17(8.0)$ \\
Sex & \\
Male & $150(71.1)$ \\
Female & $61(28.9)$ \\
Marital Status & $118(55.9)$ \\
Single & $93(44.1)$ \\
Married & $1(0.5)$ \\
Education & $19(9.0)$ \\
SLC (Class 10) & $109(51.7)$ \\
High School $(+2)$ & $82(38.9)$ \\
Bachelor & \\
Masters or Above & $41(19.4)$ \\
Position & $76(36.0)$ \\
Support & $59(28.0)$ \\
Officer & \\
Managerial &
\end{tabular}

\section{Assessment of Convergent Validity}

For assessing the convergent validity of each individual dimension of the WPS scale, standardized loadings of each item, AVE, and reliability coefficient of individual dimensions were assessed. The standardized loadings, AVE, and reliability coefficients are shown in Table 3. Standardized path estimates of all items of compassion dimension except one item are higher than .50 but the values of AVE and coefficient alpha are .42 and .60 respectively. These values suggest that this dimension lacks good convergent validity. In the case of meaningful work dimension, one item has standardized path estimate below .50, AVE is .46, and value of coefficient alpha is .85 . 


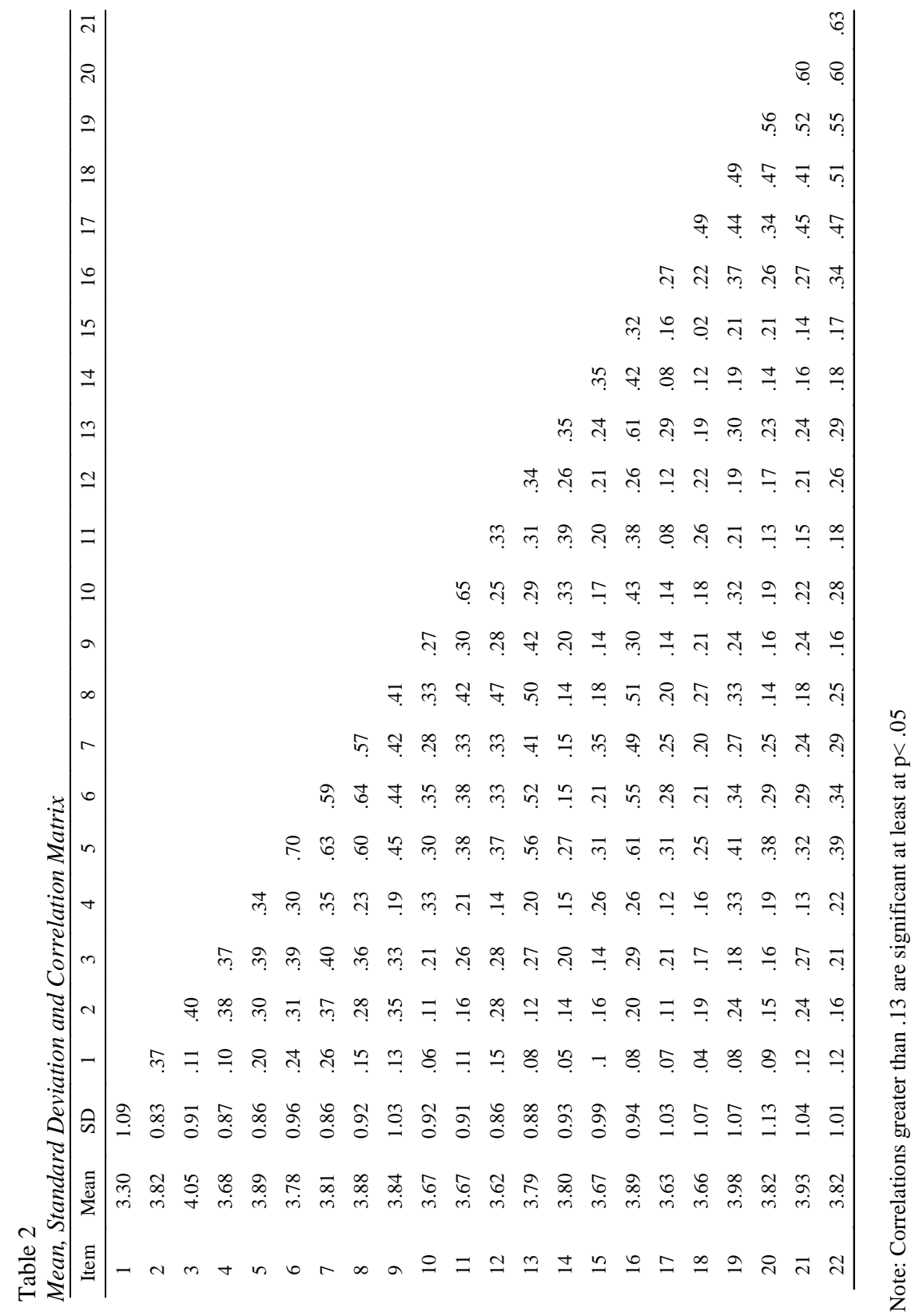


Table 3

Indicators of Convergent Validity and Reliability

\begin{tabular}{|c|c|c|c|c|c|}
\hline & Items & nate & $R^{2}$ & AVE & $\alpha$ \\
\hline \multicolumn{6}{|c|}{ Compassion } \\
\hline 1 & I can easily put myself in other people's shoes. & .34 & .11 & & \\
\hline 2 & I am aware of and sympathize with others. & .65 & .42 & .42 & .60 \\
\hline 3 & I try to help my coworkers relieve their sufferings. & .64 & .40 & & \\
\hline 4 & I am aware of my coworkers' needs. & .56 & .32 & & \\
\hline \multicolumn{6}{|c|}{ Meaningful work } \\
\hline 5 & I experience joy in my work. & .83 & .69 & .46 & .85 \\
\hline 6 & I look forward to coming to work most days. & .81 & .65 & & \\
\hline 7 & I believe other experience joy as a result of my work. & .74 & .54 & & \\
\hline 8 & My spirit is energized by my work. & .75 & .56 & & \\
\hline 9 & $\begin{array}{l}\text { I see a connection between my work and the larger social } \\
\text { good of my community. }\end{array}$ & .55 & .31 & & \\
\hline 10 & I understand what gives my work personal meaning. & .47 & .23 & & \\
\hline 11 & $\begin{array}{l}\text { The work I do is connected to what I think is important in } \\
\text { life. }\end{array}$ & .52 & .27 & & \\
\hline \multicolumn{6}{|c|}{ Transcendence } \\
\hline & $\begin{array}{l}\text { At times, I experience an energy or vitality at work that is } \\
\text { difficult to describe. }\end{array}$ & .46 & .21 & .35 & .70 \\
\hline 13 & I experience moments at work where everything is blissful. & .75 & .56 & & \\
\hline & At times, I experience happiness at work. & .44 & .19 & & \\
\hline & $\begin{array}{l}\text { I have moments at work in which I have no sense of time or } \\
\text { space. }\end{array}$ & .38 & .14 & & \\
\hline 16 & At moments, I experience complete joy and ecstasy at work. & .80 & .65 & & \\
\hline \multicolumn{6}{|c|}{ Mindfulness } \\
\hline & $\begin{array}{l}\text { I do jobs or tasks automatically, without being aware of what } \\
\text { I am doing. }\end{array}$ & .59 & .35 & .50 & .85 \\
\hline 18 & I find myself working without paying attention. & .63 & .40 & & \\
\hline 19 & $\begin{array}{l}\text { At work, I break or spill things because of carelessness, not } \\
\text { paying attention, or thinking of something else. }\end{array}$ & .73 & .53 & & \\
\hline 20 & $\begin{array}{l}\text { I rush through work activities without being really attentive } \\
\text { to them. }\end{array}$ & .74 & .55 & & \\
\hline 21 & $\begin{array}{l}\text { I go to the places on automatic pilot, and then wonder why I } \\
\text { went there. }\end{array}$ & .75 & .57 & & \\
\hline 22 & $\begin{array}{l}\text { It seems I am working automatically without much } \\
\text { awareness of what I'm doing. }\end{array}$ & .80 & .64 & & \\
\hline
\end{tabular}


The value of coefficient alpha of transcendence dimension is .70. However, one item of this dimension has standardized path estimate below .50, and the AVE is also below the cutoff value. These values suggest inadequate convergent validity of this dimension. All standardized path estimates of mindfulness dimensions are above .50, the AVE is .50, and the value of coefficient alpha is .85 . These values indicate adequate convergent validity of this dimension.

The correlations between each item and its underlying dimension ranged from .27 to .82 and squared multiple correlations $\left(R^{2}\right)$ ranged from .14 to .69 , which also demonstrate adequate convergent validity of the scale. But, the values of AVE exceeded in the case of mindfulness and transcendence, indicating a construct overlap between these dimensions.

\section{Assessment of Discriminant Validity}

Discriminant validity was examined by using the methodology presented by Hair et al. (2010). The correlation matrix and coefficient alpha are shown in Table 4. The discriminant validity values, AVE, and squared correlations values are shown in Table 5. The discriminant validity values of compassion, meaningful work and mindfulness are sufficiently below the cutoff value .85 , which indicated adequate discriminant validity of these three dimensions of WPS scale. However, transcendence dimension has discriminant value slightly above the cut off value. When the other criteria of assessing discriminant validity suggested by Hair et al. (2010), i.e., a comparison between the AVE values and squared correlations was used, three dimensions of WPS scale showed good discriminant validity. But, transcendence dimension could not meet this criterion as the squared correlation between it and meaningful work dimension is slightly higher than the AVE value (see Table 5).

Table 4

Correlation Matrix and Coefficient Alpha

\begin{tabular}{lllllllll}
\hline & & Mean & SD & 1 & 2 & 3 & 4 & 5 \\
\hline 1 & Compassion & 3.72 & .62 & .60 & & & & \\
2 & Meaningful Work & 3.79 & .67 & $.52^{* *}$ & .85 & & & \\
3 & Transcendence & 3.75 & .62 & $.38^{* *}$ & $.69^{* *}$ & .70 & & \\
4 & Mindfulness & 3.81 & .81 & $.29^{* *}$ & $.43^{* *}$ & $.40^{* *}$ & .85 & \\
5 & WPS & 3.77 & .53 & $.64^{* *}$ & $.87^{* *}$ & $.78^{* *}$ & $.75^{* *}$ & .89 \\
\hline
\end{tabular}

Note: $* * \mathrm{p}<.01$, coefficient alpha values shown in diagonal

Table 5

Discriminant Validity, AVE and Squared Correlations

\begin{tabular}{rlrrrr}
\hline & & 1 & 2 & 3 & 4 \\
\hline 1 & Compassion &. $\mathbf{4 2}$ & .27 & .14 & .08 \\
2 & Meaningful Work & .73 &. $\mathbf{4 6}$ & .48 & .18 \\
3 & Transcendence & .59 & .89 &. $\mathbf{3 5}$ & .16 \\
4 & Mindfulness & .44 & .55 & .66 & $\mathbf{. 5 0}$ \\
\hline
\end{tabular}

Note: AVE values are shown in diagonal; values at the left of diagonal are discriminant values; values at the right of diagonal are squared correlations 


\section{Discussion}

This study examined the generalizability, dimensionality, and validity of the WPS scale developed by Petchsawang and Duchon (2009) in the Nepali context. It was found that the scale, although developed with a Buddhist culture in mind and tested in Thailand, is generalizable to organizations of Nepal. The CFA of WPS dimensions, in general, demonstrate convergent validity, discriminant validity, and the scale has high internal consistency as measured by Cronbach's alpha. However, some of the dimensions of the scale failed to meet all criteria for good convergent validity. In the case of compassion dimension, the value of internal consistency reliability was satisfactory only $(\alpha=.60)$. Petchsawang and Duchon's (2009) study has also shown a relatively low value of internal consistency reliability $(\alpha=.63)$. While assessing discriminant validity, transcendence dimension could not meet one criterion of suggesting good discriminant validity. But, as its correlations with other dimensions are not high $(\rho<=.69)$ and discriminant values are significantly lower than cutoff value, this dimension can be said to have demonstrated adequate discriminant validity.

Although transcendence dimension did not demonstrate good convergent validity and discriminant validity on some assessment criteria, the findings, in general, suggest that WPS could be captured by 22 items representing four correlated but analytically distinct dimensions - 'compassion', 'mindfulness', 'meaningful work', and 'transcendence' in Nepal.

\section{Implications}

WPS is a developing discipline and there is a need for its measurement for further advancement of this field (Krahnke, Giacalone, \& Jurkiewicz, 2003). The scholars who have contributed in the development of WPS scale (e.g., Kolodinsky et al., 2008; Liu \& Robertson, 2010) also highlight the need for further refinement and validation of existing WPS scales. The present study examined the validity of a scale developed in an eastern cultural context and found that the scale is generalizable to a seemingly different context. This finding can have significant implications as the scholars interested in conducting research using this scale can be more confident about the findings of their study because of the rigorousness of the scale used while capturing the construct WPS.

\section{Limitations and Future Research Directions}

Despite this study's goal of testing the generalizability and dimensionality and cross-validating a previously developed measure of WPS, participants were taken from several organizations representing diverse sectors. Since non-probability sampling method was used in this study, there may be sample selection bias. Another limitation of this study is the sample size. For increased generalizability of the findings, future research needs to examine whether the same results could be obtained from randomly selected large sample from different organizations of the same sector of business.

This study examined convergent validity and discriminant validity of the previously developed scale. Apart from the methods used for testing convergent validity and discriminant validity in the current study, there are other methods available for testing convergent and discriminant validity. A construct's convergent validity is established when the scores obtained with two different scales measuring the same concept are highly correlated (Sekaran \& Bougie, 2010). Similarly, a construct is said to have discriminant validity when it is found to be uncorrelated to a construct that is, based on 
theory, uncorrelated to it (Sekaran \& Bougie, 2010). These techniques of convergent and discriminant validity tests were not employed in the current study. Furthermore, as Liu and Robertson (2011) point out, construct validity can be demonstrated only through many studies over time. Future studies utilizing different techniques of validity tests are needed for further validation of this scale.

Because of cross-sectional data, only the internal consistency reliability of the scale was assessed. The scale was found to have good internal consistency. However, the other aspect of reliability, that is the stability of the scale, could not be assessed as it requires longitudinal data. Therefore, further study with a longitudinal design for checking test-retest reliability is required so as to assess the stability of the scale.

\section{References}

Abdullah, A. G. K., \& Ismail, A. (2013). Validating and standardisation the scale of Malay version workplace spirituality from Malaysian school settings. International Journal of Asian Social Science, 3(6), 1418-1430.

Ashoms, D., \& Duchon, D. (2000). Spirituality at work: A conceptualization and measure. Journal of Management Inquiry, 9(2), 134-145. http://dx.doi.org/10.1177/105649260092008

Bhattacharya, S. (2013). A global spiritual index, its predictors and relationship to crime. Journal of Human Values, 19(1), 83-104. http://dx.doi.org/10.1177/0971685812470346

Case, P., \& Gosling, J. (2010). The spiritual organization: Critical reflections on the instrumentality of workplace spirituality. Journal of Management, Spirituality and Religion, 7(4), 257-282. http://dx.doi.org/10.1080/14766086.2010.524727

Central Bureau of Statistics. (2012). National population and housing census report 2011.Kathmandu, Nepal: Author.

Chawla, V., \& Guda, S. (2010). Individual spirituality at work and its relationship with job satisfaction, propensity to leave and job commitment: An exploratory study among sales professionals. Journal of Human Values, 16(2), 157-167. http://dx.doi.org/10.1177/097168581001600203

Duchon, D., \& Plowman, D.A. (2005). Nurturing the spirit at work: Impact on work unit performance. The Leadership Quarterly, 16(5), 807-833. http://dx.doi.org/10.1016/j.leaqua.2005.07.008

Garcia-Zamor, J. (2003). Workplace spirituality and organizational performance. Public Administration Review, 63(3), 355-363. http://dx.doi.org/10.1111/1540-6210.00295

Giacalone, R.A., \& Jurkiewicz, C. L. (2003). Toward a science of workplace spirituality. In R.A. Giacalone \& C.L. Jurkiewicz (Ed.), Handbook of workplace spirituality and organizational performance (pp. 3-28). Armonk, NY: M.E. Sharpe.

Gomez, R., \& Fisher, J.W. (2003). Domains of spiritual well-being and development and validation of the spiritual well-being questionnaire. Personality and Individual Differences, 35(8), 1975-1991. http://dx.doi.org/10.1016/S0191-8869(03)00045-X

Grant, D., O'Niel, K., \& Stephens, L. (2004). Spirituality in the workplace: New empirical directions in the study of the sacred. Sociology of Religion, 65(3), 265-283. http://dx.doi.org/10.2307/3712252

Hall, T. W., \& Edwards, K. J. (2002). The Spiritual Assessment Inventory: A theistic model and measure for assessing spiritual development. Journal for the Scientific Study of Religion, 41(2), 341-357. http://dx.doi.org/10.1111/1468-5906.00121

Hair, J. F., Jr., Black, W. C., Babin, B. J., \& Anderson, R. E. (2010). Multivariate data analysis: A global perspective. New Delhi, India: Pearson Education. 
Indartono, S., \& Wulandari, S. Z. (2013). Moderation effect of gender on workplace spirituality and commitment relationship: Case of Indonesian ethics. Asian Journal of Business Ethics, 3(1), 65-81. http://dx.doi.org/10.1007/s13520-013-0032-1

Karakas, F. (2010). Spirituality and performance in organizations: A literature review. Journal of Business Ethics, 94(1), 89-106. http://dx.doi.org/10.1007/s10551-009-0251-5

Krahnke, K., Giacalone, R. A., \& Jurkiewicz, C. L. (2003). Point-counterpoint: Measuring workplace spirituality. Journal of Organizational Change Management, 16(4), 396-405. http://dx.doi.org/10.1108/09534810310484154

Kolodinsky, R. W., Giacalone, R. A., \& Jurkiewicz, C. L. (2008). Workplace values and outcomes: Exploring personal, organizational and interactive workplace spirituality. Journal of Business Ethics, 81(2), 465-480. http://dx.doi.org/10.1007/s10551-007-9507-0

Krishnakumar, S., \& Neck, C. P. (2002). The "what", "why", and "how" of spirituality in the workplace. Journal of Managerial Psychology, 17(3), 153-164. http://dx.doi.org/10.1108/02683940210423060

Liu, C. H., \& Robertson, P. J. (2011). Spirituality in the workplace: Theory and measurement. Journal of Management Inquiry, 20(1), 35-50. http://dx.doi.org/10.1177/1056492610374648

Mascaro, N., Rosen, D.H., \&Morey, L.C. (2004). The development, construct validity, and clinical utility of the spiritual meaning scale. Personality and Individual Differences, 37(4), 845-860. http://dx.doi.org/10.1016/j.paid.2003.12.011

Milliman, J., Ferguson, J., Trickett, D., \& Condemi, B. (1999). Spirit and community at Southwest Airlines: An investigation of a spiritual values-based model. Journal of Organizational Change Management, 12(3), 221-233. http://dx.doi.org/10.1108/09534819910273928

Mirvis, P. H. (1997). 'Soul work' in organizations. Organization Science, 8(2), 193-206. http://dx.doi.org/10.1287/orsc.8.2.192

Mitroff, I. I., \& Denton, E. A. (1999). A study of spirituality in the workplace. Solan Management Review, 40(1), 83-92.

Pandey, A., \& Gupta, R. K. (2008). Spirituality in management: A review of contemporary and traditional thoughts and agenda for research. Global Business Review, 9(1), 65-83. http://dx.doi.org/10.1177/097215090700900105

Polley, D., Vora, J., \& SubbaNarasimha, P. N. (2005). Paying the devil is due: Limits and liabilities of workplace spirituality. International Journal of Organizational Analysis, 13(1), 50-63. http://dx.doi.org/10.1108/eb028997

Pawar, B. S. (2008). Two approaches to workplace spirituality facilitation: A comparison and implications. Leadership \& Organization Development Journal, 29(6), 544-567. http://dx.doi.org/10.1108/01437730810894195

Pawar, B. S. (2009). Some of the recent organizational behavior concepts as precursors to workplace spirituality. Journal of Business Ethics, 88(2), 245-261. http://dx.doi.org/10.1007/s10551-0089961-3

Petchsawang, P., \& Duchon, D. (2009). Measuring workplace spirituality in an Asian context. Human Resource Development International, 12(4), 459-468. http://dx.doi.org/10.1080/ 13678860903135912

Ratnakar, R., \& Nair, S. (2012). A review of scientific research on spirituality. Business Perspectives and Research, 1(1), 1-12.

Sekaran, U., \& Bougie, R. (2010). Research methods for business: A skill building approach. New Delhi, India: Wiley India. 
Sheng, C., \& Chen, M. (2012). Workplace spirituality scale design: The view of oriental culture. Business and Management Research, 1(4), 46-62. http://dx.doi.org/10.5430/bmr.v1n4p46

Srirangarajan, G. S., \& Bhaskar, R. K. (2011). Key dimensions of spirit at work - An Indian perspective. Journal of Human Values, 17(2), 93-120. http://dx.doi.org/10.1177/ 097168581101700201

Tourish, D., \& Tourish, N. (2010). Spirituality at work, and its implications for leadership and followership: A post-structuralist perspective. Leadership, 6(2), 207-224. http://dx.doi.org/ $\underline{10.1177 / 1742715010363210}$

Triandis, H. C. (1994). Culture and social behavior. New York, NY: McGraw-Hill. 